\title{
Cephalometric analysis: manual tracing of a lateral cephalogram
}

SADJ July 2019, Vol. 74 No. 6 p318 - p322

P Hlongwa

\begin{abstract}
Cephalometric analysis remains a preferred tool in the diagnosis and treatment planning of orthodontic and of orthognathic surgical cases. A cephalometric tracing can be prepared and analysed manually or by a computer using cephalometric tracing software. A number of software programmes on cephalometric analyses have been introduced but their widespread use has been restricted by cost factors, especially in situations having a constraint on resources. This report will give a step-by-step procedure to enable the identification of cephalometric points and planes used in orthodontic diagnosis and treatment planning and to facilitate the manual tracing of a lateral cephalogram.
\end{abstract}

\section{INTRODUCTION}

Cephalometrics ...literally "head measuring"... is the recording and interpretation of measurements of the skull made on standardized radiographs of the living head. Since the introduction of cephalometry by Broadbent and Hofrath in the 1930s, ${ }^{1,2}$ the cephalometric technique has been regarded as a most important tool for orthodontists and maxillo-facial surgeons engaged in studying dental malocclusions and the underlying skeletal discrepancies. Applications for cephalometric analysis include case diagnosis, treatment planning, prediction of growth and the evaluation of treatment results. ${ }^{3}$ Manual tracing of cephalometric films is performed by identifying radiographic landmarks on acetate overlays and using these reference points to construct lines, planes and angles to enable the measurement of linear and angular values, using a millimetre scale and a protractor. This manual process can be time-consuming and the measurements obtained may be subject to error. Whilst advances in computer science have led to the widespread application of computers in cephalometry, ${ }^{4}$ offering enhanced accuracy, nevertheless, the skills of manual analysis are still required.

\section{AIMS AND OBJECTIVES}

To enable the manual tracing of a cephalogram showing a true lateral view of the skull, and the identification of many of the cephalometric points and planes used in orthodontic diagnosis and treatment planning.

\section{Author affiliations:}

Phumzile Hlongwa: $B O H, B D S, M$ Dent (Ortho), Department of Orthodontics, School of Oral Health Sciences, Faculty of Health Science, University of the Witwatersrand, Johannesburg, South Africa.

Corresponding author: Phumzile Hlongwa

Department of Orthodontics, School of Oral Health Sciences, $8^{\text {th }}$ Floor, Charlotte Maxete Academic Hospital, 5 York Road, Parktown, Johannesburg, South Africa. Email: phumzile.hlongwa@wits.ac.za

\section{MATERIALS AND METHODS}

Materials required for manual cephalometric tracing

- Acetate tracing paper: a sheet $210 \mathrm{~mm} \times 160 \mathrm{~mm}$.

- Viewing box

- Protractor

- $300 \mathrm{~mm}$ ruler

- Tracing template

- Adhesive tape

- Eraser

- HB lead pencil

- 4H lead pencil

- Blue, red and green coloured pencils

Step-by step procedure

Step 1: Aligning the tracing paper on the lateral cephalogram radiograph

1.1. Draw two crosses about $3 \mathrm{~cm}$ apart on the top left hand corner of the radiograph.

1.2. Overlay the sheet of acetate tracing paper on the radiograph and attach the top edge with adhesive tape.

1.3. Trace the crosses onto the tracing paper for ease of subsequent superimpositioning of the tracing.

1.4. Write the patient's name, age and date of radiograph above the crosses on the tracing paper.

Step 2: Identify and trace hard tissue (HT) structures and identify the following hard tissue landmarks (Fig. 1)

2.1. Trace the cranial base.

2.2. Trace upper and lower central incisors, following the correct long axes.

2.3. Trace upper and lower first permanent molars in relationship to each other.

2.4. Trace the mandible and maxilla.

2.5. Sella $(\mathbf{S})$ : Mid-point of sella turcica.

2.6. Nasion (N): Midpoint of frontonasal suture.

2.7. Porion (Po) Top of external auditory meatus.

2.8. Orbitale (Or): Inferior border of orbit.

2.9. Pterygomaxillary fissure $(\mathrm{Pt})$ : most posterior and superior point on the outline of the pterygomaxillary fissure.

2.10. Condylion (Cd): Most superior point on the head of the condyle.

2.11. Articulare (Ar): a point on the posterior border of the ramus at the intersection with the basilar portion of the occipital bone.

2.12. Posterior nasal spine (PNS): Posterior point of bony hard palate.

2.13. Anterior nasal spine (ANS): Anterior point of maxilla. 
2.14. A-point: Deepest point on the maxilla below ANS.

2.15. B-point: Most posterior point on the bony curve of the mandible above pogonion.

2.16. Pogonion (Pog): Most anterior point of bony chin.

2.17. Gonion (Go): Most posterior and inferior point on the outline of the angle of the mandible.

2.18. Gnathion $(\mathbf{G n})$ : Most antero-inferior point on the bony chin.

2.19. Menton (Me): Lowest point on the symphysis of the mandible.

Step 3: Identify the soft tissue (ST) outlines and the following landmarks (Fig. 2)

3.1. Trace the soft tissue outline.

3.2. Soft tissue Glabella (G') Most prominent point in the sagittal plane between the supraorbital ridges.

3.3. Soft tissue Nasion ( $\mathbf{N}^{\prime}$ ) Deepest part of the soft tissue outline in front of Nasion.

3.4. Tip of Nose $(\mathbf{P})$ - Pronasale.

3.5. Subnasale (Sn) Junction of nasal septum and upper lip in mid-sagittal plane.

3.6. Soft tissue A-point (SLS) Deepest midline point on outline of the Superior labial sulcus.

3.7. Labialis Superior (Ls) Most anterior point on outline of upper lip (vermillion border).

3.8. Stomium Superior (Stms) Lowest midline point on outline of upper lip.

3.9. Stomium Inferior (Stmi) Highest midline point on outline of lower lip.

3.10. Labialis Inferior ( $\mathbf{L i}$ - Most anterior point on outline of the lower lip (vermillion border).

3.11. Soft tissue B-point (ILS) Deepest midline point on outline of the Inferior labial sulcus.

3.12. Soft tissue Pogonion (Pog') Most anterior point on outline of ST chin.

3.13. Soft tissue Menton (Me') Lowest point on outline of soft tissue chin.

Step 4: Connect the following landmarks (Fig. 3)

4.1. Sella and Nasion - SN line. ${ }^{5}$

4.2. Porion and Orbitale (Frankfurt Horizontal plane - FH). ${ }^{3}$

4.3. Mesiobuccal cusp of maxillary first molar and cusp of the first premolar - (Occlusal plane). ${ }^{5}$

4.4. Straight line through Gnathion(Gn) and Gonion (Go) [MP - Mandibular plane]. ${ }^{3}$

4.5. Sella and Gnathion (Y-axis). ${ }^{5}$

4.6. Nasion and A-point (NA-line). ${ }^{3}$

4.7. Nasion and B-point (NB-line). ${ }^{3}$

4.8. Nasion and Pogonion ( $\mathbf{N}$ - Pog). ${ }^{3,5}$

4.9. A-point and Pogonion (APo-line). ${ }^{6}$

Step 5: Measure the following angles (Figures 3 and 4).

5.1. Angle between $\mathrm{SN}$ line and $\mathrm{FH}$ line. ${ }^{5}$

5.2. Angle between $\mathrm{SN}$ line and Occlusal plane. ${ }^{5}$

5.3. Angle between $\mathrm{SN}$ line and Mandibular plane. ${ }^{3}$

5.4. Angle between $\mathrm{FH}$ line and Sella - Gnathion ( $\mathrm{Y}$ - axis). ${ }^{5}$

5.5. Angle between $\mathrm{SN}$ and $\mathrm{NA}$ line $\left(\mathrm{SNA}^{\circ}\right) .^{3}$

5.6. Angle between $\mathrm{SN}$ line and $\mathrm{NB}$ line $\left(\mathrm{SNB}^{\circ}\right){ }^{3}$

5.7. Difference between $\mathrm{SNA}$ and $\mathrm{SNB}=\left(\mathrm{ANB}^{\circ}\right){ }^{3}$

5.8. Angle between $\mathrm{FH}$ and NPog line (Facial angle). ${ }^{3,5}$

5.9. Angle between long axis of $U 1$ and NA line. ${ }^{3}$

5.10. Angle between long axis of $L 1$ and NB line. ${ }^{3}$

5.11. Angle between long axis of $\mathrm{U} 1$ and $\mathrm{L} 1$ (Interincisal angle). ${ }^{3,5}$

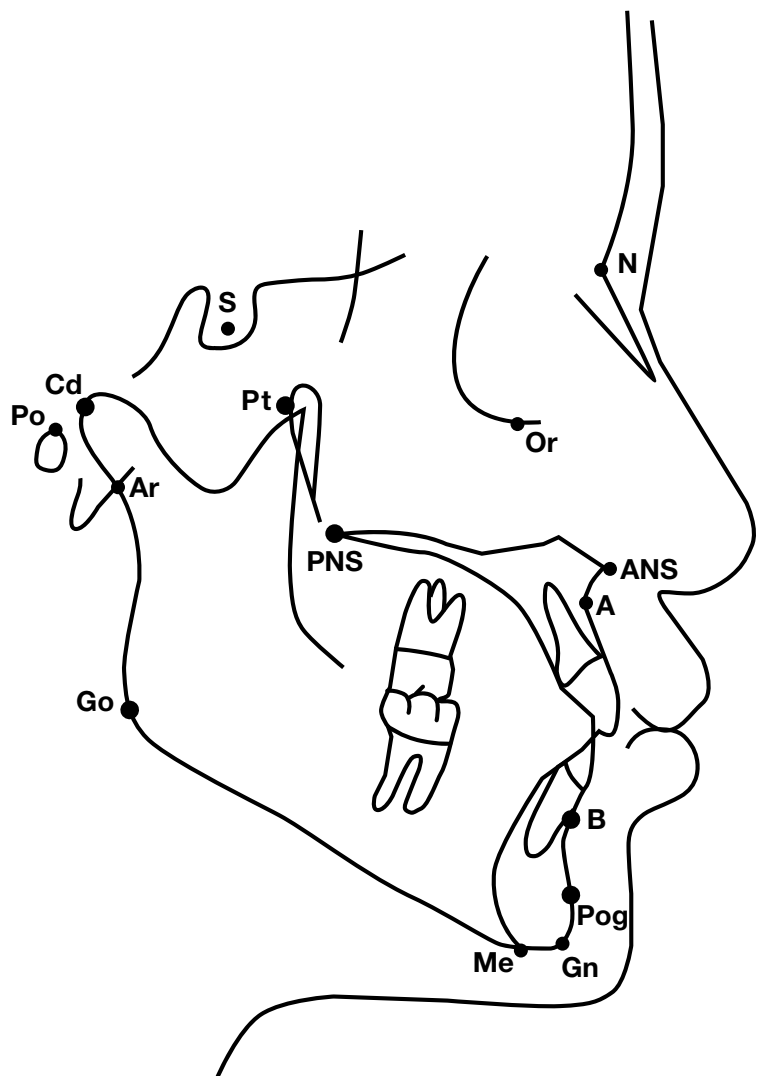

Figure 1. Cephalometric hard tissue landmarks: (S-Sella; N-Nasion; Po-Prion; Cd-Condylion; Pt-Pterygomaxillary fissure; Or-Orbitale; Ar-Artiulare; PNS-Posterior nasal spine; ANS-Anterior nasal spine; A-A point; B-B point; Pog-Pogonion; Gn-Gnathion; Me-Menton).

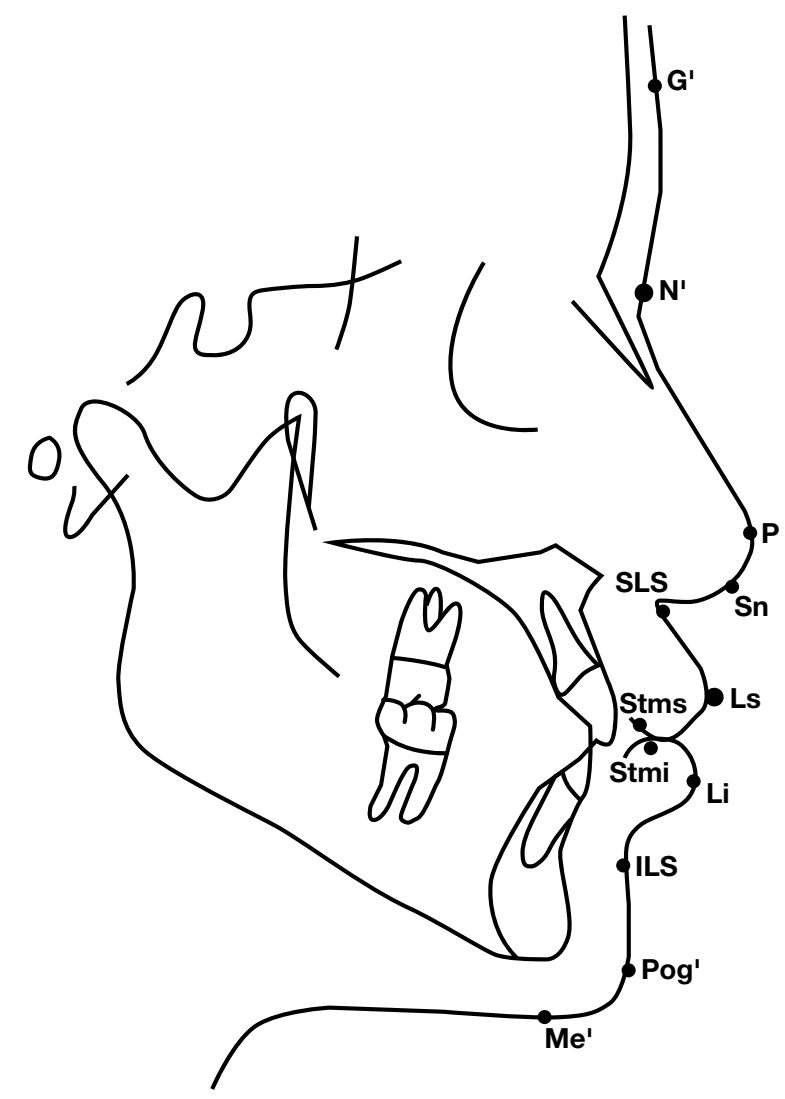

Figure 2. Cephalometric soft tissue landmarks: (G'- Soft tissue Glabella; N'-Soft tissue Nasion; P-Pronasale; Sn-Subnasale; SLS-Soft tissue A point; Ls-Labialis superior; Stms-Stomium superior; Stmi-Stomium inferior; Li-Labialis inferior; ILS-Soft tissue B point; Pog'-Soft tissue Pogonion; Me' - Soft tissue Menton). 
5.12. Total facial angle (TFA) -- G'-P-Pog': angle formed by the intersection of the line soft tissue glabella-pronasale and the extended line soft tissue pogonion-pronasale to form the contained angle for measurement. ${ }^{8-10}$

5.13. Soft tissue facial angle (FA) - G'-Sn-Pog'-angle formed by the intersection of lines subnasale-glabella and pogonion-subnasale extended (measured at the upper contained angle). ${ }^{8}$

5.14. Soft tissue facial angle (STFA) - $\mathrm{N}^{\prime}-\mathrm{Pog}$ ' and $\mathrm{FH}$ : angle formed by the intersection of the line soft tissue pogonion-soft tissue nasion and the Frankfort Horizontal plane, measured as the lower contained angle. ${ }^{8}$

5.15. Merrifield's Z angle (ZA) - Pog' to most protrusive lip, extended to $\mathrm{FH}$ : the angle between the "profile line" and the Frankfort horizontal plane. ${ }^{11}$

5.16. Nasolabial angle (NA) - Cm-Sn-Ls: Angle between the intersection of lines tangent to the columella and upper lip..$^{8-10}$

5.17. Pogonion-labial angle (MLA) - Li-ILS-Pog': Angle between the intersection of the line labialis inferiusto inferior labial sulcus and a line tangent to the soft tissue pogonion, passing through labialis inferior. ${ }^{9,10}$

5.18. Pogonion-menton angle (PMA) - Pog'-Me': Angle between the intersection of lines tangent to the soft tissue pogonion and soft tissue menton. ${ }^{9,10}$

5.19. Holdaway angle $(H A)$ : Angle formed between the soft tissue facial plane line (soft tissue nasionpogonion) and the $\mathrm{H}$ line ${ }^{8}$ (soft tissue pogonion to labialis inferior).

Step 6: Measure the following linear measurements (mm) (Fig 3)

6.1. SN length. ${ }^{12}$

6.2. NB line to A-point (Convexity). ${ }^{6}$

6.3. Most anterior point of labial U1 to NA-line. ${ }^{3}$

6.4. Most anterior point of labial L1 to NB-line. ${ }^{3}$

6.5. APog-line to incisal edge of $L 1 .^{3}$

6.6. Distance between $A$ and $B$ perpendicular points on the occlusal plane (Wits analysis). ${ }^{7}$

6.7. Upper lip length (ULL): Discrepancy in the vertical dimension, extent of upper incisor visibility in resting position. ${ }^{9}$ (upper stomium to ST subnasale).

6.8. Lower lip length (LLL): Discrepancy in the vertical dimension, extent of the lower lip curl, presence or absence of labio-mental fold. ${ }^{9}$ (lower stomium to ST pogonion).

6.9. Upper lip prominence (ULP-B line): Protrusive/ retrusive upper lip relative to the $B$ Line. ${ }^{9}$

6.10. Lower lip prominence (LLP-B line): Protrusive/ retrusive lower lip relative to the $B$ Line. ${ }^{9}$

6.11. Lower lip position (LLP-H): Retruded or protruded lower lip relative to $\mathrm{H}$ line. ${ }^{8}$

6.12. Interlabial gap (ILG): The space between the upper and lower lips when they are relaxed, with the head in a normal upright position and the teeth in centric relation. ${ }^{8-10}$

6.13. Hard tissue pogonion to soft tissue pogonion (Pog-Pog'): Soft tissue thickness measured between the hard tissue pogonion and soft tissue pogonion. ${ }^{9}$

6.14. Hard tissue menton to soft tissue menton (Me-Me'): Soft tissue thickness measured between the hard tissue menton and soft tissue menton. ${ }^{9}$

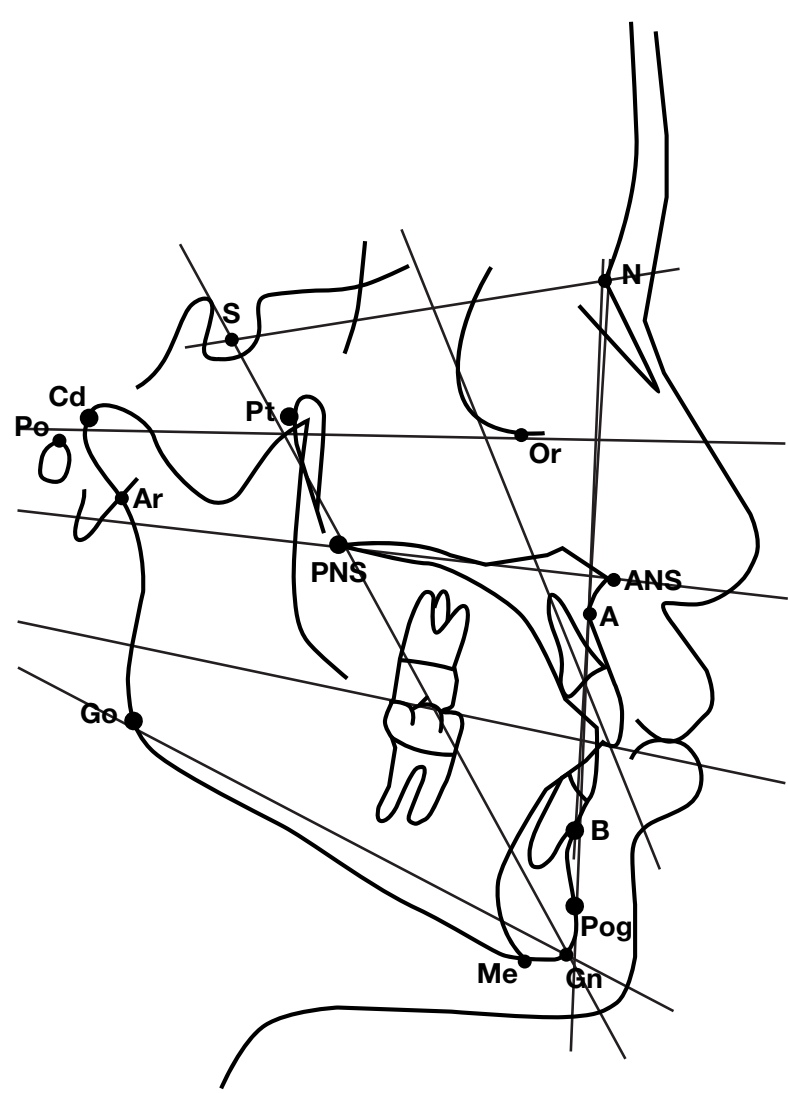

Figure 3. Cephalometric tracing: lines are constructed to join the landmarks for analysis of angular relationships.

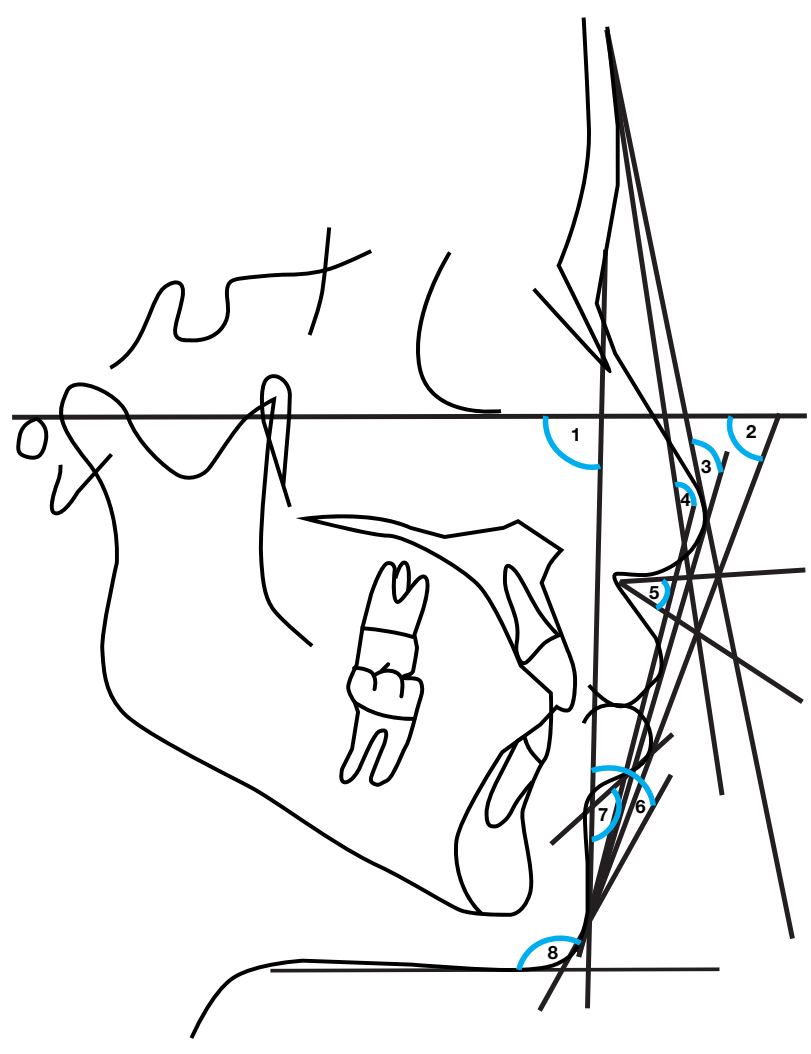

Figure 4. Soft tissue angles: (1- Soft tissue facial angle; $2-Z$ angle; 3 -Total facial angle; 4 - Facial angle; 5 - Nasiolabial angle; 6 - Holdaway angle; 7-Pogonion-labial angle; 8-Pogonion-menton angle) 
Table 1. Cephalometric Analysis Template.

\begin{tabular}{|c|c|c|c|c|c|c|c|}
\hline \multicolumn{8}{|c|}{ Cephalometric Analysis Template } \\
\hline & $\begin{array}{l}\text { Cephalometric } \\
\text { measurements }\end{array}$ & $\begin{array}{c}\text { Reference } \\
\text { norm values }\end{array}$ & Pre-Tx & Post-Tx & \multicolumn{3}{|c|}{ Interpretatior } \\
\hline \multirow{16}{*}{ Skeletal } & Facial Angle & & & & $\mathrm{N}$ & $<$ & $>$ \\
\hline & Pog - NB & & & & $\mathrm{N}$ & $\mathrm{P}$ & R \\
\hline & N-Pog - A & & & & N & $P$ & $R$ \\
\hline & SNA & & & & N & $P$ & R \\
\hline & SNB & & & & $\mathrm{N}$ & $P$ & $\mathrm{R}$ \\
\hline & ANB & & & & 1 & II & III \\
\hline & WITS & & & & I & II & III \\
\hline & Y-Axis & & & & N & $<$ & $>$ \\
\hline & SN Length & & & & N & $<$ & $>$ \\
\hline & $\mathrm{FH}$ to $\mathrm{SN}$ & & & & $\mathrm{N}$ & $<$ & $>$ \\
\hline & PP to SN & & & & N & $<$ & $>$ \\
\hline & OP to SN & & & & N & $<$ & $>$ \\
\hline & MP to SN & & & & $\mathrm{N}$ & $<$ & $>$ \\
\hline & Gonial Angle & & & & N & $<$ & $>$ \\
\hline & UFH & & & & $\mathrm{N}$ & $<$ & $>$ \\
\hline & LFH & & & & $\mathrm{N}$ & $<$ & $>$ \\
\hline \multirow{6}{*}{ Dento-alveolar } & U1to $\mathrm{NA}^{\circ}$ & & & & $\mathrm{N}$ & $\mathrm{P}$ & $\mathrm{R}$ \\
\hline & U1to NA mm & & & & N & $\mathrm{P}$ & $\mathrm{R}$ \\
\hline & L1 to $\mathrm{NB}^{\circ}$ & & & & $\mathrm{N}$ & $P$ & $\mathrm{R}$ \\
\hline & L1 to NB mm & & & & N & P & R \\
\hline & Inter-Incisal $^{\circ}$ & & & & N & $<$ & $>$ \\
\hline & $\mathrm{AP}^{\circ}$ & & & & N & P & $\mathrm{R}$ \\
\hline \multirow{16}{*}{ Soft Tissue } & & & & & & & \\
\hline & TFA & & & & N & $<$ & $>$ \\
\hline & FA & & & & N & $<$ & $>$ \\
\hline & STFA & & & & $\mathrm{N}$ & $<$ & $>$ \\
\hline & ZA & & & & $\mathrm{N}$ & $<$ & $>$ \\
\hline & NA & & & & $N$ & $<$ & $>$ \\
\hline & MLA & & & & N & $<$ & $>$ \\
\hline & PMA & & & & $\mathrm{N}$ & $<$ & $>$ \\
\hline & UL mm & & & & $\mathrm{N}$ & $<$ & $>$ \\
\hline & LL mm & & & & N & $<$ & $>$ \\
\hline & ULP-B mm & & & & $\mathrm{N}$ & $<$ & $>$ \\
\hline & LLP-B mm & & & & $\mathrm{N}$ & $<$ & $>$ \\
\hline & LLP-H mm & & & & $N$ & $<$ & $>$ \\
\hline & Inter-labial gap & & & & $\mathrm{N}$ & $<$ & $>$ \\
\hline & Pog-Pog' & & & & $\mathrm{N}$ & $<$ & $>$ \\
\hline & Me-Me' & & & & $\mathrm{N}$ & $<$ & $>$ \\
\hline
\end{tabular}

Cephalometric Diagnosis 
6.15. Measure distance between perpendicular anterior facial height lines - (Nasion to ANS and ANS to menton). ${ }^{9}$

\section{Step 7: Place your values in the table on p321 (Table 1) and analyze your findings}

\section{DISCUSSION}

Six steps have been presented in the manual completion of a cephalometric tracing. This tracing incorporates a number of cephalometric analyses., ${ }^{3,5-12}$ By comparison of angular measurements with reference norm values the clinician will interpret the results of the analysis to give a diagnosis of the presenting dento-skeletal soft tissue pattern. Comparison of the findings of the pre-treatment and post-treatment measurements will allow the clinician to assess the outcome of treatment.

\section{CONCLUSION}

Manual cephalometric tracing still has a role to play in orthodontic diagnosis as well as in undergraduate and postgraduate teaching and training in Orthodontics. Jackson et al. ${ }^{13}$ reported a high reproducibility of landmarks and measurements for both hand-tracing and digitized cephalometry. In financially constrained situations where computer cephalometric software is not affordable, manual tracing is still a useful tool. A cephalometric analysis template is proposed for easy documentation of the cephalometric measurements.

\section{References}

1. Broadbent $\mathrm{BH}$. A new X-ray technique and its application to orthodontia. The Angle Orthodontist 1931; 1(2):45-66.

2. Hofrath $\mathrm{ODH}$. Die bedeutung der röntgenfern-und abstandsaufnahme für die diagnostik der kieferanomalien. Fortschritte der Orthodontik in Theorie und Praxis 1931;1(2):232-58.

3. Steiner CC. The use of cephalometrics as an aid to planning and assessing orthodontic treatment: report of a case. American Journal of Orthodontics. 1960;46(10):721-35.

4. Rudolph DJ, Sinclair PM, Coggins JM. Automatic computerized radiographic identification of cephalometric landmarks. American Journal of Orthodontics and Dentofacial Orthopedics 1998;113(2):173-9.

5. Downs WB. The role of cephalometrics in orthodontic case analysis and diagnosis. American Journal of Orthodontics. 1952;38(3):162-82.

6. Ricketts RM. Cephalometric analysis and synthesis. The Angle Orthodontist. 1961;31(3):141-56.

7. Jacobson A. The "Wits" appraisal of jaw disharmony. American Journal of Orthodontics 1975;67(2):125-38.

8. Holdaway RA. A soft-tissue cephalometric analysis and its use in orthodontic treatment planning. Part I. American Journal of Orthodontics 1983;84(1):1-28.

9. Arnett GW, Jelic JS, Kim J, et al. Soft tissue cephalometric analysis: diagnosis and treatment planning of dentofacial deformity. American Journal of Orthodontics and Dentofacial Orthopedics 1999;116(3):239-53.

10. Bergman RT. Cephalometric soft tissue facial analysis. American Journal of Orthodontics and Dentofacial Orthopedics 1999;116(4):373-89.

11. Merrifield LL. The profile line as an aid in critically evaluating facial esthetics. American Journal of Orthodontics 1966;52(11):804-22.

12. Björk A. Roentgen cephalometric growth analysis. Congenital anomalies of the face and associated structures Springfield, III: Charles C Thomas. 1961:237-50.

13. Jackson PH, Dickson GC, Birnie DJ. Digital image processing of cephalometric radiographs: a preliminary report. British Journal of Orthodontics. 1985;12(3):122-32.

\section{Do the CPD questionnaire on page 337}

The Continuous Professional Development (CPD) section provides for twenty general questions and five ethics questions. The section provides members with a valuable source of CPD points whilst also achieving the objective of CPD, to assure continuing education. The importance of continuing professional development should not be underestimated, it is a career-long obligation for practicing professionals.

\section{Online CPD in 6 Easy Steps}

1 Go to the SADA website www.sada.co.za

2 Log into the 'member only' section with your unique SADA username and password.

3 Select the CPD navigation tab.

4 Select the questionnaire that you wish to complete.

5 Enter your multiple choice answers. Please note that you have two attempts to obtain at least $70 \%$.

6 View and print your CPD certificate. 